\section{Mutagenesis and Biotechnology Techniques as Tools for Selecting New Stable Diploid and Tetraploid Olive Genotypes and Their Dwarfing Agronomical Characterization}

\author{
Eddo Rugini ${ }^{1}$ and Cristian Silvestri \\ Department of Agriculture and Forestry Sciences, University of Tuscia, Via \\ San Camillo de Lellis s.n.c., 01100 Viterbo, Italy
}

\author{
Marilena Ceccarelli \\ Department of Chemistry, Biology and Biotechnology, University of Perugia, \\ Via Elce di Sotto 8, 06123 Perugia, Italy
}

Rosario Muleo and Valerio Cristofori

Department of Agriculture and Forestry Sciences, University of Tuscia, Via San Camillo de Lellis s.n.c., 01100 Viterbo, Italy

Additional index words. Olea europaea, olive mutants, dwarfing rootstocks, olive intercom-
patibility, intensive olive orchard, stable olive tetraploids

\begin{abstract}
In Olea europaea L. subsp. europaea, tetraploid genotypes do not exist in nature. Herein, we report the first example of selection of tetraploid olive plants, obtained by combining physical mutagenesis and biotechnology techniques. Stable tetraploid $(4 n)$ and diploid $(2 n)$ genotypes were isolated in vitro through shoot-tip fragmentation of two mixoploid mutants derived from the gamma irradiation of self-incompatible Leccino and self-compatible Frantoio cultivars. In this study, the stable mutants FRM5-4n, FRM5-2n, LM3-4n, and LM3-2n were characterized in the field for vegetative and reproductive behavior with the aim to use them as varieties or dwarfing rootstocks. The stable $4 n$ genotype of Leccino acquired self-fertility whereas the $4 n$ Frantoio maintained it. A high and constant yield was showed by LM3-2n during 9 years of observation, maintaining the same oil quality as the Leccino wild type (wt). Moreover, the LM3-2n acquired the capacity to be intercompatible with the diploid mutant Leccino dwarf (LD) and with the Leccino wt. This acquired property would allow for a reduction of heterozygosity in the offspring, if crossed with each other for some generations and with the Leccino $w t$, because it is a sort of self-fertilization. When used as rootstocks, both $4 n$ and $2 n$ Leccino mutants proved to be very effective for reducing the scion size of the high-vigor Canino cultivar, which is well known for its excellent extravirgin oil. Finally, it was demonstrated that the self-grafting of vigorous cultivar caused a reduction in plant size, thus suggesting that it is possible to produce semidwarf plants from vigorous genotypes to consider them in high-density olive orchards.
\end{abstract}

In recent years, in many olive oil producing countries, the research has been focused on the innovation of orchard management with the aims to reduce production costs and to increase yield and oil quality. For these purposes, attempts have been made to introduce intensive or superintensive orchards, or adopt new training systems (Connors et al., 2014; Freixa et al., 2011). In several countries, there has been a rapid increase of highdensity olive cultivation regarding a limited number of mainly traditional cultivars, whereas possible new varieties with suitable

Received for publication 15 Feb. 2016. Accepted for publication 28 Apr. 2016.

Most of the funding was provided by the FILAS project "MIGLIORA" of Latium Region.

${ }^{1}$ Corresponding author. E-mail: rugini@unitus.it. programmed crosses or in alternative to use varieties, since both do not require waiting a long time to reach the phenotypic stability of the adult phase as the seedling. Until now, little was known about the mechanisms involved in the dwarfing ability of rootstocks. Several hypotheses about the role of physiological stimuli and/or anatomical characters have been made (scion/rootstock disaffinity, water influence, hormonal factors, competition for carbohydrates or nutrients), each supported by experimental data. It was found that no single mechanism influences plant physiology. Rather, the vigor reduction induced by rootstock appears to be the result of a more complex interaction of various factors (Atkinson et al., 2003; Basile et al., 2003; Cohen and Naor, 2002; Gascó et al., 2007; Nardini et al., 2006; Solari et al., 2006; Soumelidou et al., 1994; Trifilò et al., 2007).

Mutagenesis induction is a useful technique for accelerating the genetic improvement of both varieties and rootstocks, but the difficulties observed in isolating stable mutants for vegetative propagation represent a strong deterrent. The first mutants in olive, showing different vegetative habits, were obtained $\approx 40$ years ago, following the gamma ray irradiation of plants from Ascolana Tenera and Moraiolo cultivars. These mutants showed low agronomic value (Donini and Roselli, 1972) and cytogenetic instability. Subsequently, some mutants with compact phenotype from cultivars Leccino and Frantoio irradiated cuttings were able to reduce plant size when used as rootstock (Pannelli et al., 1990, 1992). Cytogenetic analyses showed that the mutants, named Frantoio Compact (FC) and Leccino Compact (LC), were mixoploids, whereas a mutant showing a dwarf vegetative habit, obtained from cv. Leccino and therefore named LD, proved to be the only stable diploid mutant (Rugini et al., 1996). The LD mutant produced fruits similar to those of the wild type genotypes, but bloomed at least 1 week later, while both FC and LC produced normal and large-sized fruits, suggesting that they originated from diploid or tetraploid cells, respectively, as validated by Rugini et al. (1996). Recently, Caporali et al. (2014) observed that most of the flowers produced by the mixoploid LC plants are tetraploids, characterized by floral structures larger than in the corresponding diploid plants, due to the increase of the cell size, which also occurred in the fruits. However, polyploidy had little effect on the LC fruit size, because these showed a less elongated shape than in cv. Leccino.

Diploid and tetraploid olive plants were isolated from the mixoploid LC and FC mutants by means of the in vitro shoot-tip fragmentation technique (Rugini et al., 1996). The tetraploid shoots were easily distinguished from the diploid or mixoploid ones, both in in vitro culture and in the greenhouse, at the early growing stages, due to their wider and thicker leaves.

It is well known that there are no tetraploid genotypes in the cultivated olive (O. europaea subsp. europaea); in fact, this is diploid with basic chromosome number $n=23$, and a nuclear DNA content ranging from $2.3 \mathrm{pg} / 1 \mathrm{C}$ 
DNA in cultivars Leccino and Frantoio (Rugini et al., 1996), to $3.90 \mathrm{pg} / 2 \mathrm{C}$ in cv. Dolce Agogia and $4.66 \mathrm{pg} / 2 \mathrm{C}$ in cv. Pendolino (Bitonti et al., 1999). Loureiro et al. (2007) observed a nuclear DNA content ranging from 2.90 to $3.20 \mathrm{pg} / 2 \mathrm{C}$ in wild olive.

On the contrary, tetraploid and hexaploid individuals were detected respectively in the subspecies cerasiformis and maroccana of the olive complex O. europaea (Besnard et al., 2008; Rallo et al., 2003). In particular, it was hypothesized that tetraploid cerasiformis could be derived from the hybridization between the ancestors of the subspecies guanchica and europaea (Besnard et al., 2008; Rugini et al., 2011). Polyploidy is a very common condition in the plant kingdom, changing the organization and function of the genome at both genetic and epigenetic level (Comai, 2005). It is well known that polyploidization usually increases the cell dimensions, the fruit size, and sometimes the plants show a better adaptability than their diploid parents.

This study focuses on the vegetative and reproductive characterization of the stable tetraploid and diploid mutants obtained from the shoot apex fragmentation of mixoploid genotypes, grown under field conditions, and on the evaluation of their effect on the vigorous cultivar Canino when used as rootstocks.

\section{Materials and Methods}

Plant material. Stable tetraploid mutants Frantoio and Leccino, and diploid Frantoio and Leccino plants, were evaluated in field trials. These genotypes were obtained from the mixoploid genotypes FC and LC after in vitro shoot apex fragmentation, which produced several lines (Rugini et al., 1996). In this study, only plants belonging to the lines FRM5 for Frantoio and LM3 for Leccino were analyzed and compared with Frantoio and Leccino $w t$. Frantoio and Leccino were used as controls (hereinafter named Frantoio $w t$ and Leccino $w t$ ). The tetraploid mutants were named FRM5-4n and LM3-4n, whereas the diploid plants were termed FRM5- $2 n$ and LM3-2n. LD, a further diploid mutant characterized by Rugini et al. (1996), was used in some experiments.

Semi-hardwood cuttings were collected from diploid and tetraploid adult micropropagated plants FRM5 and LM3 to produce new plants to be used for the experiments. The ploidy level of the twigs used as cuttings was assessed as described below. The new plantlets were transplanted into pots and bred in greenhouse conditions for 2 years, then transferred in the field at the experimental farm of Tuscia University (Viterbo, Central Italy).

Furthermore, with the aim to use the mutants as dwarfing rootstocks, both diploid and tetraploid LM3 cuttings were grafted with the cv. Canino, and compared with Canino grafted on Leccino $w t$, and both ungrafted and selfgrafted Canino. In addition, the self-grafting of LM3- $2 n$ and LM3-4n was carried out. Bark grafting was performed in the spring, at a height of $20 \mathrm{~cm}$ from ground level in 1-year-old potted plants. Similar to the grafted plants, the ungrafted ones were cut at the same height from the ground. The field trial was carried out in the following spring.

All the plants transferred in the field, both mutant genotypes and grafting combinations, were cultivated in free shape form with a central axis spaced $2.5 \times 4 \mathrm{~m}$ and drip irrigated whenever necessary during the summer. At the end of the winter, a slight pruning was performed every year by removing only suckers and vigorous shoots. The observations were carried out on 10 plants for each genotype and grafting combination, for a period of 9 years. The plant height and the trunk cross-sectional area (TCSA) forthwith above the grafting point were recorded for 3 years starting from the fourth leaf on field. Data were analyzed using analysis of variance (ANOVA) and the mean and the difference among mean were separate using Tukey's test $(P<0.01)$.

Feulgen cytophotometry. Feulgen cytophotometry was carried out to verify the ploidy level of the twigs used as cuttings, collected from adult plants FRM5 and LM3 in the field. Twenty vegetative buds were randomly selected from the canopy of one plant for each line, during active shoot growing. The buds were fixed in ethanol acetic acid $(3: 1 \mathrm{v} / \mathrm{v})$ and treated with an aqueous solution of pectinase $(8 \%)$, cellulase $(7 \%)$, and macerozyme $(2 \%)$, for $105 \mathrm{~min}$ at $37^{\circ} \mathrm{C}$. The apical meristem was isolated from each bud and squashed under a coverslip in a drop of $60 \%$ acetic acid. The coverslips were removed after freezing at $-80{ }^{\circ} \mathrm{C}$ and the preparations were Feulgen stained following hydrolysis in $1 \mathrm{M} \mathrm{HCl}$ at $60{ }^{\circ} \mathrm{C}$ for $8 \mathrm{~min}$. After staining, each slide was washed three times for $10 \mathrm{~min}$ in $\mathrm{SO}_{2}$ water, before dehydration and mounting in DPX (BDH Chemicals, VWR International, Ltd). As proposed by Bennett and Leitch (2005), squashes of root tips from a single plantlet of Pisum sativum cv. Minerva Maple (4C $=19.46$ $\mathrm{pg}$ ) were concurrently stained with each group of slides and used as a standard reference to make all results comparable. Feulgen/DNA absorption measurements were taken at early prophase using a Leitz MPV3 microscope photometer (Wetzlar, Hesse, Germany) equipped with a mirror scanner at a wavelength of $550 \mathrm{~nm}$.

Leaf, flower, and fruit traits and oil quality. Ten adult leaves collected from each of three plants at the end of the growing season, were weighed and leaf area was determined by means of an area meter; immediately before starting to open the flowers, in five twigs for each plant, the number of flowers per each inflorescence and the weight of each flower were determined. From the same plants, thirty fruits were collected $145 \mathrm{~d}$ after full bloom and weighed. Data were analyzed using ANOVA and the difference among mean were separate using Tukey's test $(P<0.01)$.

A sensory and standard official chemical analysis was carried out (Reg. CEE n. 2568/ 1991 and Decreto MIPAAF 18/06/2014) to start a preliminary evaluation of the oil quality (data not shown).

Self-and intercompatibility determination. To evaluate the self-compatibility of the mutant genotypes and to compare it with Leccino $w t$ and Frantoio wt, 15 flowering twigs for each genotype were placed in paper bags, closed with cotton wool, and tied with a plastic thread. The bags remained closed for 3 weeks, and then the fruit set was calculated.

For the evaluation of intercompatibility, another 15 twigs were collected and immediately used for hand cross-pollination experiments, and then the bags were strongly shaken three times for three subsequent days to facilitate pollination. Also, in this case, the bags remained closed for 3 weeks from pollination, before calculating the fruit set.

The genotypes blooming with delay were hand pollinated by dispersion of pollen stored in petri dishes $\left(\right.$ at $+4{ }^{\circ} \mathrm{C}$ ) inside the bags in according to the same procedure. Pollen viability was checked by $2 \%$ acetic carminium staining and observations under an optical microscope, before and after storing.

The experiments were repeated for two consecutive years.

\section{Results and Discussion}

Ploidy-level assessment and blooming ability of FRM5 and LM3 genotypes. Cytophotometric analyses were carried out to assess the ploidy level of the diploid and
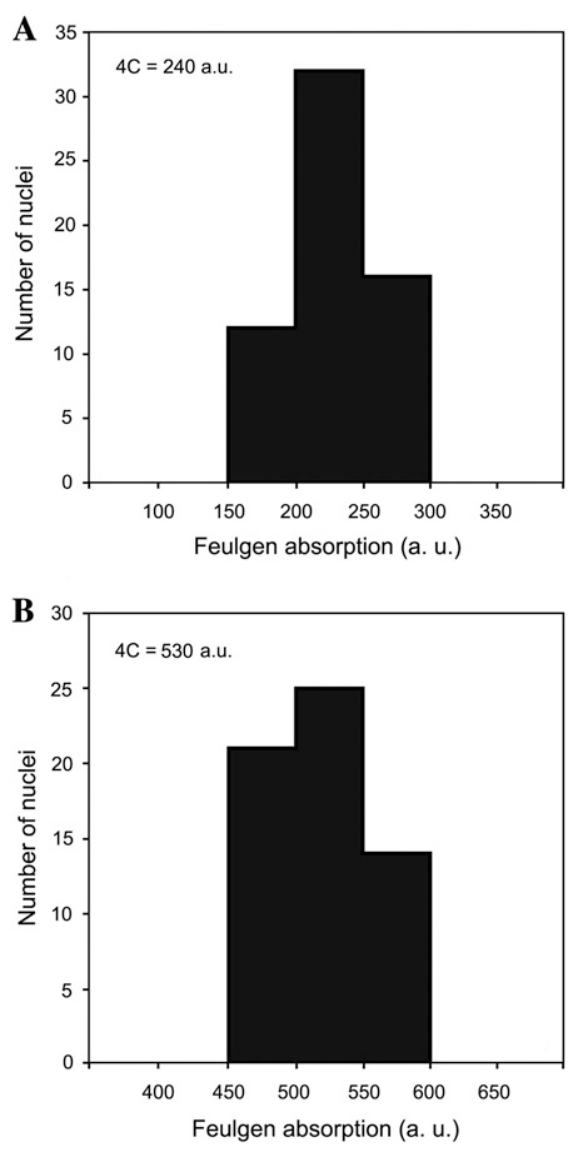

Fig. 1. Feulgen absorption (arbitrary units) of early prophases in shoot meristems of (A) cv. Frantoio wild type and (B) somatic mutant FRM5$4 n$. Each histogram shows the values measured on 60 nuclei per plant. 
tetraploid FRM5 and LM3 plants, by using shoot apices. The analyses confirmed the diploid status of all $2 n$ mutants (data not shown) and the tetraploid condition of several $4 n$ mutants, of which an example has been reported in Fig. 1, whereas few other supposed $4 n$ plants resulted still in mixoploids, even though the presence of diploid cells was very low (data not shown). Therefore, the latter plants were excluded from this study. Anyway, the shoot-tip fragmentation technique proved to be a suitable method for isolating plants with stable ploidy level. Shoot organogenesis from somatic tissues, particularly from leaf petioles (Mencuccini and Rugini, 1993), would be a better way to isolate stable plants from chimeric tissues, since shoot differentiation takes place from a single cell. However, at present, shoot regeneration from mature tissues is not very efficient in olive cultivars.

The tetraploid selected plants were easily recognized from the early stages of in vitro culture due to their larger and thicker leaves. They were also able to bloom promptly in pots from the first year of cultivation. Both the derived in vitro diploid and tetraploid plants, although originating from the same bud by means of apex fragmentation, flowered for the first time 2 years later than the tetraploid ones. On the contrary, the potted plants obtained by cuttings from the same adult donor plants (FRM5 and LM3) bloomed abundantly from the first year (Fig. 2), and in the subsequent years only LM3 showed abundant and constant cropping in all years of field observations. On the contrary FRM5- $2 n$ genotype showed alternate bearing similar to both FRM5-4n and LM3-4n mutants and a low fruit set ability even with artificial pollination, as occurred in the mixoploid mutant LC (Caporali et al., 2014). Both the original (primary) mixoploids and our selected tetraploid plants produced fewer inflorescences with larger flowers per panicle than the respective Leccino $w t$ (Fig. 3A and C) and Frantoio $w t$.

Leaf, flower, and fruit traits and oil quality. The leaf area and fresh weight in both the $4 n$ mutants LM3 and FRM5 proved to be $\approx 2$-fold higher than in the respective $2 n$ mutants and $w t$ varieties (Table 1).

Regarding the reproductive traits, the $4 n$ plants showed a reduction in the number of flowers per inflorescence. Anyway, each single flower was more than 2-fold in weight in comparison with those of the $2 n$ plants, but the same increase was not recorded for the fruit weight. Furthermore, in both $2 n$ mutants, the fruit weight was lower, particularly in the Leccino mutant (LM3-2n) (Table 1). The fruits of the $4 n$ plants appeared heterogeneous for the size, whereas those of $2 n$ plants were uniform and characterized by an earlier pigmentation (Fig. 3C). Unlike FRM5-2n, the LM3- $2 n$ genotype produced flowers in abundance (Fig. 3B), and it was cropped regularly throughout the study. Preliminary studies regarding the taste and composition of the oil appeared similar to those extracted from Leccino and Frantoio wt drupes at the same ripening stage, although the oil of LM3- $2 n$ mutant, observed for 2 years, had a slight balsamic taste, in 1 year only (data not shown).

Self- and intercompatibility determination. The $4 n$ plants of both Leccino and Frantoio started blooming 3-4 d earlier than the $2 n$ plants. The mutant LD, bloomed $\approx 7-12 \mathrm{~d}$ later than all the other genotypes, depending on the year. However, pollen storing at $+4{ }^{\circ} \mathrm{C}$ and the use of genotypes coming from two different geographical area (one at 300 asl and the other on $460 \mathrm{asl}$, and located $200 \mathrm{~km}$ in the north), enabled us to carry out pollination successfully.

The results of the crosses and self-pollination experiments are reported in Table 2. The controlled pollination showed that the FRM5- $4 n$ mutants maintained the typical self-fertility of Frantoio $w t$, whereas the LM3-4n, obtained from the notoriously self-sterile cv. Leccino, acquired self-compatibility. Polyploidy can affect sexuality by providing selective advantages

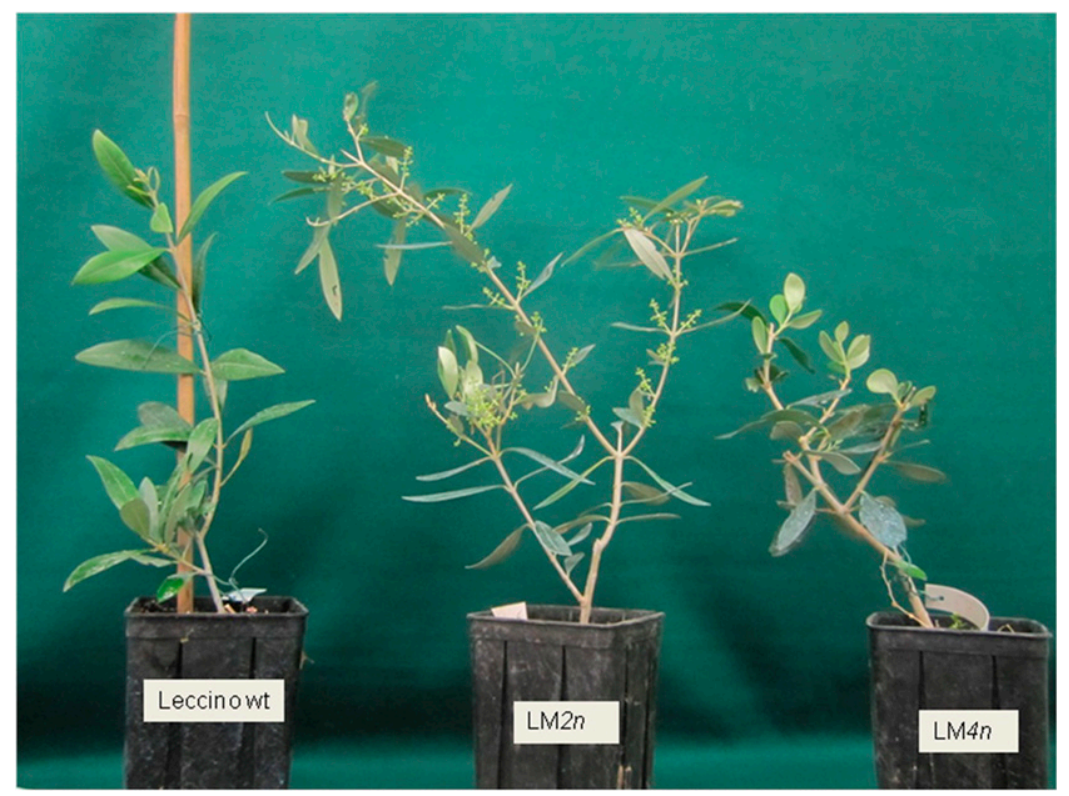

Fig. 2. Potted coeval plantlets derived from subapical cuttings of 5-year-old field-growing plants: note the precocity and high capacity of LM3-2n plant to differentiate flowers.
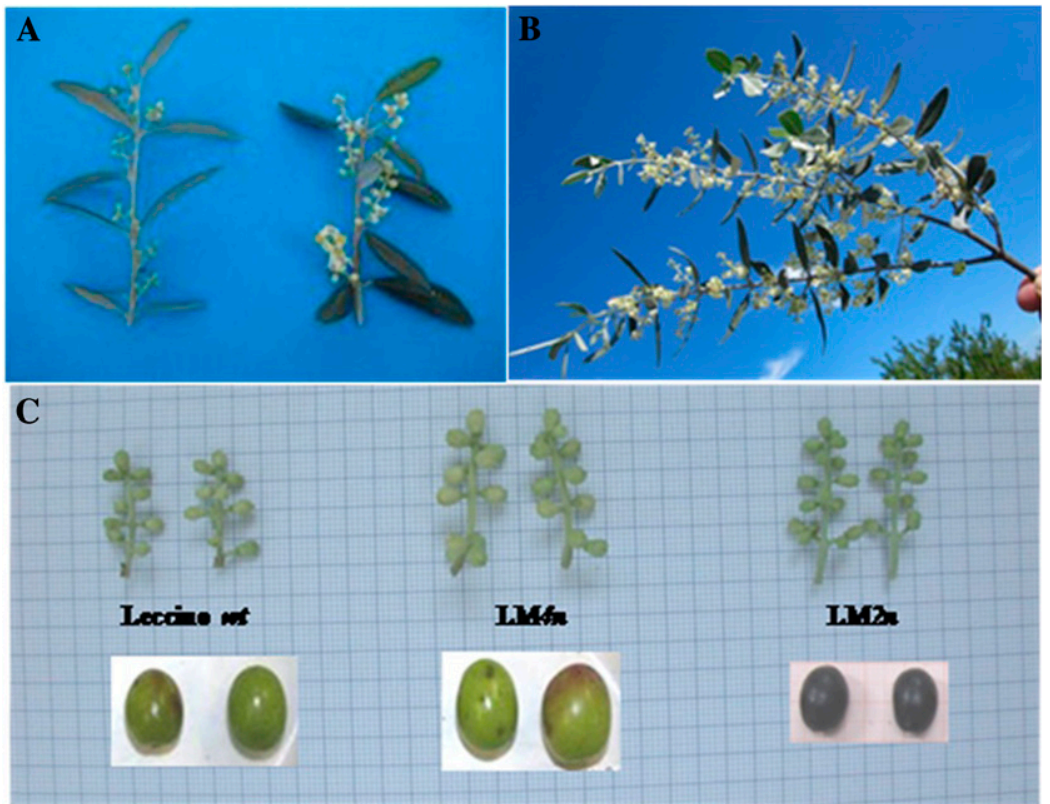

Fig. 3. (A) Fruiting twig of the LM3-4n mutant (right) showing a precocious blooming in respect to cv. Leccino wild type ( $w t$ ) (left). (B) Fruiting twigs of the LM3-2n genotype at blooming stage: note the abundant flowers and the equilibrium between vegetative and reproductive phase. (C) Comparison of inflorescences and fruits of Leccino $w t$, LM3-4n, and LM3-2n. The latter are characterized by different fruit size and ripening, and different flower size. 
and favoring the onset of asexual reproduction, associated with the capacity of polyploidy to make better use of heterozygosis, such as the buffering effect of gene redundancy on mutation and the facilitation of reproduction through selffertilization (Comai, 2005). However, both Leccino and Frantoio tetraploids showed alternate bearing, and the fruit set always had very low results over 9 years of observation, both with free and artificial pollination.

Regarding crosses among diploid genotypes, surprisingly, Leccino wt became interfertile with its $2 n$ mutants and, in addition, the $2 n$ mutants also became interfertile among themselves (Table 2). Although pollen contamination during artificial pollination should be excluded, considering the accuracy of the method used in this experiment, the progeny parentage analysis by molecular approaches will be considered in the future, since some authors reported possible risk of contamination (Arbeiter et al., 2014; Díaz et al., 2007). Moreover, high fruit set was observed when the LD mutant was used as pollen donor and Leccino $w t$ as female parent, while Leccino $w t$ used as pollen donor proved to be less fertile (Table 2). The LM3-2n genotype has proved to be an excellent pollinator, both when it has been crossed with Leccino $w t$ and with the LD mutant, producing high fruit set (Table 2) along 2 years of observation. This was not only due to its abundant pollen production and viability, but also for its high flower density and constant blooming over the years. These characteristics, together with the observed high constant cropping capacity over the years and the tolerance to Spilocea oleagina (Rugini et al., 2016), make LM3$2 n$ genotype also a suitable candidate for high-density cultivation, even if fruit size was not optimal (Fig. 3C).

Plant growth of ungrafted and grafted plants. The observations carried out on fieldgrown plants from the 4th to the 9th year after plantation showed that, generally, both LM3$4 n$ and FRM5- $4 n$ had mean values of plant height and TCSA lower than the LM3-2n, FRM5-2n, and the respective control plants $(w t)$. The only exception was the TCSA of FRM5-4n at the 4th year growth, because the value, although lower than in the other Frantoio genotypes, resulted not statistically different (Table 3 ). It has to be noted that the Leccino and Frantoio $4 n$ mutants that were still mixoploid (not included in this study) showed similar plant size reduction (data not shown). This is in accordance with the behavior of the polyploid plants for which it has been observed that the change of the ploidy level is strictly related to an increase of the genomic content that usually increases the cell volume, producing a change in the relationships with the cell components. The increase of both chromatin amount and nuclear envelop surface change the stoichiometry of the interactions between chromatin and envelop-bound proteins (Comai, 2005). However, not necessarily the larger cells of polyploid individuals would lead to a larger body, as previously observed also in our material (Rugini et al., 1996), but a mechanism regulating the organ growth could be established to compensate for cell size increase (Caporali et al., 2014; Comai, 2005; Tsukaya, 2008).

Regarding the $2 n$ mutants, only the TCSA of LM3-2n resulted statistically smaller than the Leccino $w t$ at 9 th year of growth. This reduction could be due to the heavy cropping that occurred in the previous years, not observed in FRM5, which showed an alternate bearing.

Concerning the effect of grafting, plant size reduction was observed in all grafted combinations, both self-grafted and grafted with other genotypes (Table 4; Fig. 4). In particular, in Canino grafted on Leccino $w t$, the reduction of the plant size was slighter, yet not statistically significant, than in selfgrafting, whereas the mutants LM3-2n and LM3-4 $n$ behaved as dwarfing rootstocks (Table 4). Although the genotypes LM3-2n and LM3- $4 n$ showed a different morphological behavior and vigor, it is interesting to note that both were able to reduce the plant

size of the vigorous cv. Canino scion similarly to LD rootstock (Nardini et al., 2006; Rugini et al., 2003). The causes of the scion size reduction on the dwarfing rootstock LD have been extensively investigated (Gascó et al., 2007; Nardini et al., 2006; Trifilò et al., 2007). All these authors report that the "dwarfing syndrome" in olive may arise from hydraulic constraints imposed by the roots.

However, a deeper study is necessary to understand the reasons of dwarfing ability of our mutants. According to our results, with the objective to reduce plant size, it is essential to take into account self-grafting. The results obtained (Table 5) proved that this technique reduced the size of the bimember plant in all three self-grafted genotypes tested (i.e., Canino, LM3-2n and LM3-4n). Self-grafting could be particularly useful for reducing plant size, when a minimal plant reduction is required to establish highdensity olive groves.

Conclusions, remarks, and perspectives. The synergistic use of traditional mutagenesis and biotechnology techniques is seldom

Table 1. Leaf and flower parameters of $2 n$ and $4 n$ Leccino and Frantoio mutants in comparison with their respective cultivars wild type $(w t)$.

\begin{tabular}{lccccc}
\hline Genotype & Leaf area $\left(\mathrm{cm}^{2}\right)$ & Leaf wt $(\mathrm{mg})$ & No. of flowers/inflorescence & Flower wt $(\mathrm{mg})$ & Fruit wt (g) \\
\hline Leccino $w t$ & $4.80 \mathrm{c}$ & $176 \mathrm{~b}$ & $11.31 \mathrm{a}$ & $13 \mathrm{~b}$ & $2.35 \mathrm{a}$ \\
LM3-2n & $4.15 \mathrm{~b}$ & $163 \mathrm{~b}$ & $9.72 \mathrm{a}$ & $19 \mathrm{~b}$ & $1.43 \mathrm{~b}$ \\
LM3-4n & $6.99 \mathrm{a}$ & $310 \mathrm{a}$ & $7.59 \mathrm{~b}$ & $37 \mathrm{a}$ & $3.19 \mathrm{c}$ \\
& & & & & \\
Frantoio $w t$ & $4.47 \mathrm{~b}$ & $160 \mathrm{~b}$ & $11.87 \mathrm{a}$ & $21 \mathrm{~b}$ & $3.14 \mathrm{a}$ \\
FRM5-2 $n$ & $4.01 \mathrm{~b}$ & $150 \mathrm{~b}$ & $9.95 \mathrm{a}$ & $34 \mathrm{a}$ & $3.05 \mathrm{a}$ \\
FRM5-4n & $6.25 \mathrm{a}$ & $340 \mathrm{a}$ & $9.16 \mathrm{~b}$ & \\
\hline
\end{tabular}

Different letters within the groups indicate significant difference at $P<0.01$.

Table 2. Results of self- and intercompatibility determination expressed as drupes/inflorescence ratio, carried out on the $2 n$ and $4 n$ Leccino mutants and Leccino and Frantoio wild type (wt).

\begin{tabular}{|c|c|}
\hline Test & Compatibility drupes/inflorescence (\%) \\
\hline \multicolumn{2}{|l|}{ Self-pollination } \\
\hline Leccino $w t$ & No \\
\hline Frantoio $w t$ & Yes $(33 \pm 1.2)$ \\
\hline $\operatorname{LD}(2 n)$ & No \\
\hline LM3-2n & No \\
\hline LM3-4n & Yes $(25 \pm 0.9)$ \\
\hline FRM5-2n & Yes $(30 \pm 1.3)$ \\
\hline FRM5-4n & Yes $(20 \pm 0.6)$ \\
\hline \multicolumn{2}{|l|}{ Crosses } \\
\hline FRM5-4n (†) × LM3-4n (ठ̋) & Yes $(15 \pm 0.7)$ \\
\hline 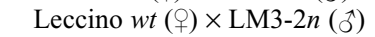 & Yes $(55 \pm 1.5)$ \\
\hline Leccino $w t($ () $) \times \operatorname{LD}($ (ぇ) & Yes $(40 \pm 0.9)$ \\
\hline $\mathrm{LD}(+) \times \mathrm{LM} 3-2 n($ (̋) & Yes $(45 \pm 1.0)$ \\
\hline LD $(+) \times$ Leccino $w t(\precsim)$ & Yes $(10 \pm 0.3)$ \\
\hline FRM5-4n (q) $\times$ LM3-4n (ふ̋) & Yes $(15 \pm 0.7)$ \\
\hline
\end{tabular}

LD = Leccino dwarf.

Table 3. Vegetative traits measured in $2 n$ and $4 n$ mutants of Leccino and Frantoio in three different years of field trial, compared with the respective cultivars wild type $(w t)$.

\begin{tabular}{|c|c|c|c|c|c|c|}
\hline \multirow[b]{2}{*}{ Genotypes } & \multicolumn{2}{|c|}{ (4th yr) } & \multicolumn{2}{|c|}{ (6th yr) } & \multicolumn{2}{|c|}{ (9th yr) } \\
\hline & $\overline{\mathrm{Ht}}(\mathrm{m})$ & $\operatorname{TCSA}\left(\mathrm{cm}^{2}\right)$ & $\overline{\mathrm{Ht}}(\mathrm{m})$ & $\operatorname{TCSA}\left(\mathrm{cm}^{2}\right)$ & $\overline{\mathrm{Ht}}(\mathrm{m})$ & $\operatorname{TCSA}\left(\mathrm{cm}^{2}\right)$ \\
\hline Leccino $w t$ & $4.60 \mathrm{a}$ & $120.19 \mathrm{a}$ & $5.10 \mathrm{a}$ & $210.35 \mathrm{a}$ & $5.60 \mathrm{a}$ & $300.15 \mathrm{a}$ \\
\hline LM3-2n & $4.65 \mathrm{a}$ & $118.19 \mathrm{a}$ & $5.20 \mathrm{a}$ & $171.55 \mathrm{a}$ & $5.55 \mathrm{a}$ & $224.59 \mathrm{~b}$ \\
\hline LM3-4n & $2.50 \mathrm{~b}$ & $59.98 \mathrm{~b}$ & $2.95 \mathrm{~b}$ & $81.56 \mathrm{~b}$ & $4.80 \mathrm{~b}$ & $175.77 \mathrm{~b}$ \\
\hline Frantoio $w t$ & $4.40 \mathrm{a}$ & $110.11^{\mathrm{Ns}}$ & $5.30 \mathrm{a}$ & $187.52 \mathrm{a}$ & $5.65 \mathrm{a}$ & $268.66 \mathrm{a}$ \\
\hline FRM5-2n & $4.20 \mathrm{a}$ & $115.20^{\mathrm{Ns}}$ & $5.70 \mathrm{a}$ & $194.00 \mathrm{a}$ & $5.90 \mathrm{a}$ & $237.10 \mathrm{a}$ \\
\hline FRM5-4n & $2.70 \mathrm{~b}$ & $83.39^{\mathrm{Ns}}$ & $3.30 \mathrm{~b}$ & $136.39 \mathrm{~b}$ & $4.00 \mathrm{~b}$ & $179.60 \mathrm{~b}$ \\
\hline
\end{tabular}

TCSA $=$ trunk cross-sectional area

Different letters within the groups indicate significant difference at $P<0.01$; NS $=$ nonsignificant. 
Table 4. Effect of different rootstocks on the vegetative traits of cv. Canino 9-year-old plants.

\begin{tabular}{lcc}
\hline Grafting combination & $\mathrm{Ht}(\mathrm{m})$ & TCSA $\left(\mathrm{cm}^{2}\right)$ \\
\hline Canino ungrafted & $5.80 \mathrm{a}$ & $296.26 \mathrm{a}$ \\
Canino/Canino & $4.90 \mathrm{~b}$ & $177.54 \mathrm{~b}$ \\
Canino/Leccino $w t$ & $5.10 \mathrm{~b}$ & $142.40 \mathrm{~b}$ \\
Canino/LM3-2n & $4.00 \mathrm{c}$ & $68.95 \mathrm{c}$ \\
Canino/LM3-4n & $4.20 \mathrm{c}$ & $101.76 \mathrm{c}$ \\
\hline
\end{tabular}

TCSA $=$ trunk cross-sectional area.

Different letters within the groups indicate significant difference at $P<0.01$.

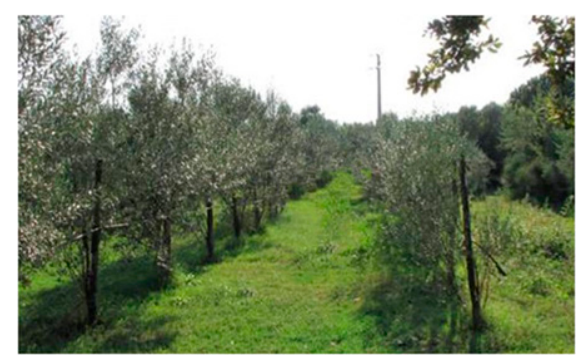

Fig. 4. Self-grafted cv. Canino (left) and Canino grafted on the mutated Leccino (right) in the experimental field (plants at the sixth leaf on field).

Table 5. Effect of self-grafting on the vegetative traits of the genotypes studied. The traits were measured on 9-year-old plants.

\begin{tabular}{lcc}
\hline Self-grafting & $\mathrm{Ht}(\mathrm{m})$ & TCSA $\left(\mathrm{cm}^{2}\right)$ \\
\hline Canino ungrafted & $5.80 \mathrm{a}$ & $296.26 \mathrm{a}$ \\
Canino/Canino & $4.90 \mathrm{~b}$ & $177.54 \mathrm{~b}$ \\
LM3-2 $n$ ungrafted & $5.50 \mathrm{a}$ & $224.58 \mathrm{a}$ \\
LM3-2n/LM3-2n & $3.20 \mathrm{~b}$ & $142.04 \mathrm{~b}$ \\
LM3-4n ungrafted & $4.80 \mathrm{a}$ & $175.88 \mathrm{a}$ \\
LM3-4n/LM3-4n & $3.80 \mathrm{~b}$ & $103.18 \mathrm{~b}$ \\
\hline
\end{tabular}

TCSA $=$ trunk cross-sectional area.

Different letters within the groups indicate significant difference at $P<0.01$.

put into practice to support the traditional genetic improvement of woody fruit plants. The shoot apex fragmentation of mutagenized mixoploid olive plants that is useful for selecting stable mutants when in vitro shoot organogenesis, which arises from a single cell, cannot be practiced efficiently due to a recalcitrant genotype or to a failure of the polyploidy cells differentiation caused by diplontic selection. When in vitro techniques are efficient in recovering stable plants, mutagenesis should be coupled, since it accelerates the genetic improvement, particularly in species with a long juvenile phase, such as olive. Furthermore, it may be possible to apply mutagenesis to produce dwarf mutants, because now there is enough experience in woody plants regarding the use of suitable plant material, the dose of mutagens, and the time of treatment. Because of the difficulties encountered in producing stable mutants, mutagenesis was almost abandoned in the past, in favor of different technologies such as genetic engineering. This technique, though promising, has encountered serious difficulties in establishing itself, mainly for ideological reasons supported by the adverse media communication culminated, in Italy, with the ban of field trials of transgenic plants. These facts seem to encourage food companies to return to the use of mutagenesis technology, especially in those countries that reject genetically modified food, not only because it is cheaper and unregulated, but also because it prompts the random shuffling of genes in a plant genome. The interesting results that we obtained, encourage us to pursue this direction. In this way, $4 n$ olive plants and other interesting $2 n$ mutants that would be used as varieties and rootstocks have been produced. The tetraploid mutants, compared with the $2 n$ standard genotypes, proved to have a more compact growth habit, larger fruits, and the same oil quality. Moreover, they acquired self-fertility. The availability of these genotypes encourages us to use them to produce offspring by crossbreeding to obtain smaller plants, including $3 n$ plants to be used as rootstocks or for ornamental purposes. Furthermore, they could be also used to carry out targeted studies in an attempt to shed more light on the role of the ploidy level in the plant vigor reduction. Moreover, the Leccino $2 n$ mutants, although retaining auto-incompatibility, achieved interfertility with other $2 n$ mutants of the same cultivar and with the self-sterile Leccino $w t$ donor genotype. This could be useful for genetic improvement since the reciprocal crosses allow for a reduction in heterozygosity. These crosses represent a sort of selffertilization, reaching an "almost pure line" after several crosses. In addition, the selected LM3- $2 n$ mutant, characterized by high and constant cropping capacity, maintained the same oil characteristics and the same tolerance to fungal disease, $S$. oleagina, of the Leccino $w t$ and appears to be a suitable candidate to be used in modern high-density olive orchards, whereas further investigations are needed to assess their performance in different environmental conditions, both with the evaluation of oil composition and sensory analysis, before releasing them for a possible commercial use.

Mutagenesis, which enables us to produce several mutagenized populations, combined with innovative screening methods such as molecular analyses would also enable us to identify traits difficult to detect with conventional breeding and traditional phenotypic observation methods. In this context, the application of this molecular investigation on $2 n$ and $4 n$ LM3 mutants may help to understand the biological reasons behind the processes that lead to the dwarfing effect and to other acquired traits. Moreover, since it is possible to reduce the size of plants by selfgrafting of the elite cultivars, this innovative approach could prove to be useful for producing semidwarf plants for intensive olive orchards.

\section{Literature Cited}

Arbeiter, A.B., J. Jakše, and D. Bandelj. 2014. Paternity analysis of the olive variety "Istrska Belica" and identification of pollen donors by microsatellite markers. Scientific World J., doi: 10.1155/2014/208590.
Atkinson, C.J., M.A. Else, L. Taylor, and C.J. Dover. 2003. Root and stem hydraulic conductivity as determinants of growth potential in grafted trees of apple (Malus pumila Mill.). J. Expt. Bot. 54:1221-1229

Basile, B., J. Marsal, and T.M. DeJong. 2003. Daily shoot extension growth of peach trees growing on rootstocks that reduce scion growth is related to daily dynamics of stem water potential. Tree Physiol. 23:695-704.

Bennett, D. and I.J. Leitch. 2005. Nuclear DNA amounts in angiosperms: Progress, problems and prospects. Ann. Bot. 95:45-90.

Besnard, G., C. Garcia-Verdugo, R. Rubio de Casas, U.A. Treier, N. Galland, and P. Vargas. 2008. Polyploidy in the olive complex (Olea europaea): Evidence from flow cytometry and nuclear microsatellite analyses. Ann. Bot. 101: 25-30.

Bitonti, M.B., R. Cozza, A. Chiappetta, A. Contento, S. Minelli, M. Ceccarelli, M.T. Gelati, F. Maggini, L. Baldoni, and P.G. Cionini. 1999. Amount and organization of the heterochromatin in Olea europaea and related species. Heredity 83:188-195.

Caporali, S., S.B.M. Hammami, I. Moreno-Alías, H.F. Rapoport, B. Chiancone, M.A. Germanà, and A. Rosati. 2014. Effects of tetraploidy on olive floral and fruit biology. Scientia Hort. 179:198-203.

Cohen, S. and A. Naor. 2002. The effect of three rootstocks on water use, canopy conductance and hydraulic parameters of apple trees and predicting canopy from hydraulic conductance. Plant Cell Environ. 25(1):17-28.

Comai, L. 2005. The advantages and disadvantages of being polyploidy. Nat. Rev. Genet. 6:836846.

Connors, D.J., M. Gómez-del-Campo, M.C. Rousseaux, and P.S. Searles. 2014. Structure, management and productivity of hedgerow olive orchards: A review. Scientia Hort. 169:71-93.

Díaz, A., A. Martín, P. Rallo, and R. De la Rosa. 2007. Cross-compatibility of the parents as the main factor for successful olive breeding crosses. J. Amer. Soc. Hort. Sci. 132:830-835.

Donini, B. and U. Roselli. 1972. Briscola. Nuova cultivar di olivo a sviluppo compatto. Rivista di Ortoflorofrutticoltura Italiana 66:103-114.

Fontanazza, G., F. Bartolozzi, and G. Vergari. 1998. Fs-17. Frutticoltura 5:61

Freixa, E., J.M. Gil, J. Tous, and J.F. Hermoso. 2011. Comparative study of the economic viability of high- and super-high-density olive orchards in Spain. Acta Hort. 924:247-254.

Gascó, A., S. Salleo, E. Gortan, and A. Nardini. 2007. Seasonal changes in the ion-mediated increase of xylem hydraulic conductivity in stems of three evergreens: Any functional role? Physiol. Plant. 129:597-606.

Loureiro, J., E. Rodriguez, A. Costa, and C. Santos. 2007. Nuclear DNA content estimations in wild olive (Olea europaea L. ssp. europaea var. sylvestris Brot.) and Portuguese cultivars of O. europaea using flow cytometry. Genet. Resources Crop Evol. 54:21-25.

Mencuccini, M. and E. Rugini. 1993. In vitro shoot regeneration from olive cultivar tissue. Plant Cell Tiss. Org. Cult. 32:283-288.

Nardini, A., A. Gascò, F. Raimondo, E. Gortan, M.A. Lo Gullo, T. Caruso, and S. Salleo. 2006. Is rootstock-induced dwarfing in olive an effect of reduced plant hydraulic efficiency? Tree Physiol. 26:1137-1144.

Pannelli, G., F. Famiani, and E. Rugini. 1992. Effects of the change on ploidy levels on anatomical, cytological, reproductive, growth performance and polyamine contents, in mutants 
of olive irradiated olive plants. Acta Hort. 317: 209-218.

Pannelli, G., F. Famiani, E. Rugini, C. Bignami, S. Natali, and P. Mannino. 1990. Preliminary characterization of olive somatic mutants from gamma irradiated Frantoio and Leccino plantlets. Acta Hort. 286:77-80.

Rallo, L., D. Barranco, R. De la Rosa, and L. Leon. 2008. 'Chiquitita'olive. HortScience 43:529-531.

Rallo, P., I. Tenzer, C. Gessler, L. Baldoni, G. Dorado, and A. Martín. 2003. Transferability of olive microsatellite loci across the genus. Olea. Theor. Appl. Genet. 107:940-946.

Reg. (CEE) n. 2568/91 and Decreto MIPAAF 18/06/ 2014.

Rugini, E., V. Cristofori, and C. Silvestri. 2016. Genetic improvement of olive (Olea europaea L.) by conventional and in vitro biotechnology methods. Biotechnol. Adv., doi: 10.1016/ j.biotechadv.2016.03.004.
Rugini, E., C. De Pace, P. Gutierrez-Pesce, and R. Muleo. 2011. Olea, p. 79-117. In: C. Kole (ed.). Wild crop relatives: Genomic and breeding resources, temperate fruits, temperate fruits. Springer-Verlag Berlin Heidelberg.

Rugini, E., G. Pannelli, M. Ceccarelli, and M. Muganu. 1996. Isolation of triploid and tetraploid olive (Olea europaea L.) plants from mixoploid cv 'Frantoio' and 'Leccino' mutants by in vivo and in vitro selection. Plant Breed. 115:23-27.

Rugini, E., G. Pannelli, A. Sonnoli, G. Bartolini, and S. De Angelis. 2003. Impiego di genotipi a sviluppo contenuto per facilitare l'impiego di macchine scavallatrici operanti in continuo per la raccolta integrale delle olive. Frutticoltura 1:57-61.

Solari, L.I., S. Johnson, and T.M. Dejong. 2006. Hydraulic conductance characteristics of peach (Prunus persica) trees on different rootstocks are related to biomass production and distribution. Tree Physiol. 26(10):1343-1350.

Soumelidou, K., N.H. Battey, P. John, and J.R. Barnett. 1994. The anatomy of the developing bud union and its relationship to dwarfing in apple. Ann. Bot. (Lond.) 74:605-611.

Trifilò, F., M.A. Lo Gullo, A. Nardini, F. Pernice, and S. Salleo. 2007. Rootstock effects on xylem conduit dimensions and vulnerability to cavitation of Olea europea L. Trees Struct. Funct. 21:549-556.

Tsukaya, H. 2008. Controlling size in multicellular organs: Focus on the leaf. PLoS Biol. 6:1373-1376.

Vivaldi, G.A., G. Strippoli, S. Pascuzzi, A.M. Stellacci, and S. Camposeo. 2015. Olive genotypes cultivated in an adult high-density orchard respond differently to canopy restraining by mechanical and manual pruning. Scientia Hort. 192:391-399. 